13,04

\title{
Состав нанокомпозитов из тонких слоев олова на пористом кремнии, сформированных методом магнетронного распыления
}

\author{
(C) А.С. Леньшин ${ }^{1}$, В.М. Кашкаров ${ }^{1}$, Э.П. Домашевская ${ }^{1}$, П.В. Середин ${ }^{1}$, \\ А.Н. Бельтюков ${ }^{2}$, Ф.З. Гильмутдинов ${ }^{2}$ \\ ${ }^{1}$ Воронежский государственный университет, \\ Воронеж, Россия \\ ${ }^{2}$ Физико-технический институт УрО РАН, \\ Ижевск, Россия \\ E-mail: lenshinas@mail.ru \\ (Поступила в Редакцию 7 июля 2016 г. \\ В окончательной редакции 31 августа 2016 г.)
}

С использованием методов растровой электронной микроскопии и рентгеновской фотоэлектронной спектроскопии проведены исследования особенностей морфологии и состава поверхности нанокомпозитов из тонких слоев олова на пористом кремнии, сформированных методом магнетронного распыления. Обнаружено, что сформированные нанокомпозиты в зависимости от толщины осажденного слоя олова различаются между собой соотношением основных фаз: диоксида олова, субоксида и металлического олова. При этом доля окисленного олова в фазовом составе композитов уменьшается от поверхности к объему образца. Установлено, что осаждение нанослоев олова не приводит к значительному изменению фазового состава подложки пористого кремния.

Работа выполнена при поддержке гранта Президента РФ (МК-4865.2016.2) и Министерства образования и науки РФ в рамках государственного задания вузам в сфере научной деятельности на 2014-2016 гг. (проект № 740, задание № 3.130.2014/K).

DOI: 10.21883/FTT.2017.04.44282.284

\section{1. Введение}

В настоящее время большое внимание привлекают материалы для мультисенсорных систем, многофункциональной оптоэлектроники и полупроводниковые устройства на их основе $[1,2]$. Модифицированный осаждением металла или металлооксида слой пористого кремния (por-Si) может быть интересен для подобных практических приложений. Создание газочувствительных композитных материалов с высокой чувствительностью и селективностью, в том числе на основе олова, совмещенное $\mathrm{c}$ традиционной кремниевой технологией, представляет интерес и для неинвазивной медицинской экспресс-диагностики [2-5]. При этом наноструктуры и нанокомпозиты на основе пористого кремния, такие как металл/por-Si и металлооксид/por-Si, могут проявлять и интересные адсорбционные и оптические свойства [5-7]. Кроме того, процесс создания подобных МДП-структур (МДП - металл-диэлектрик-полупроводник) и нанокомпозитов путем осаждения металлов в пористый кремний такими классическими методами, как магнетронное распыление, электрохимическое осаждение, золь-гель-методика, сравнительно дешев и совместим с традиционной технологией обработки кремниевых полупроводниковых структур.

В зависимости от метода осаждения, толщины и морфологии получившейся пленки, нанокомпозита или нанонити состав и свойства металлосодержащих структур могут сильно варьироваться [6-10]. Подобные структуры могут быть полностью окислены или иметь только тонкую пленку совершенного или дефектного оксида на поверхности, оставаясь преимущественно металлическими в объеме [8-10]. Характеристики наноструктур на основе олова и кремния могут меняться в процессе естественного старения и после различных внешних воздействий $[11,12]$. Поэтому и с прикладной, и с фундаментальной точки зрения важно в данной области проводить детальные последовательные исследования морфологии, состава и функциональных характеристик таких наноструктур и тонких слоев в привязке к конкретной методике получения при конкретных условиях и их сравнение с эталонными объемными образцами и уже известными результатами.

В настоящей работе с использованием рентгеновской фотоэлектронной спектроскопии и растровой электронной микроскопии (РЭМ) проведены исследования морфологии и состава нанокомпозитов из тонких слоев металлического олова на пористом кремнии, сформированных методом магнетронного распыления слоев олова различной толщины на поверхность пористого кремния.

\section{2. Методы получения и исследования нанокомпозитов $\mathrm{Sn} /$ por-Si}

Пористый кремний был получен электрохимическим травлением кремниевых монокристаллических пластин $c$-Si (100) n-типа проводимости с удельным сопротивлением $0.2 \Omega \cdot \mathrm{cm}$. Использовался стандартный раствор 

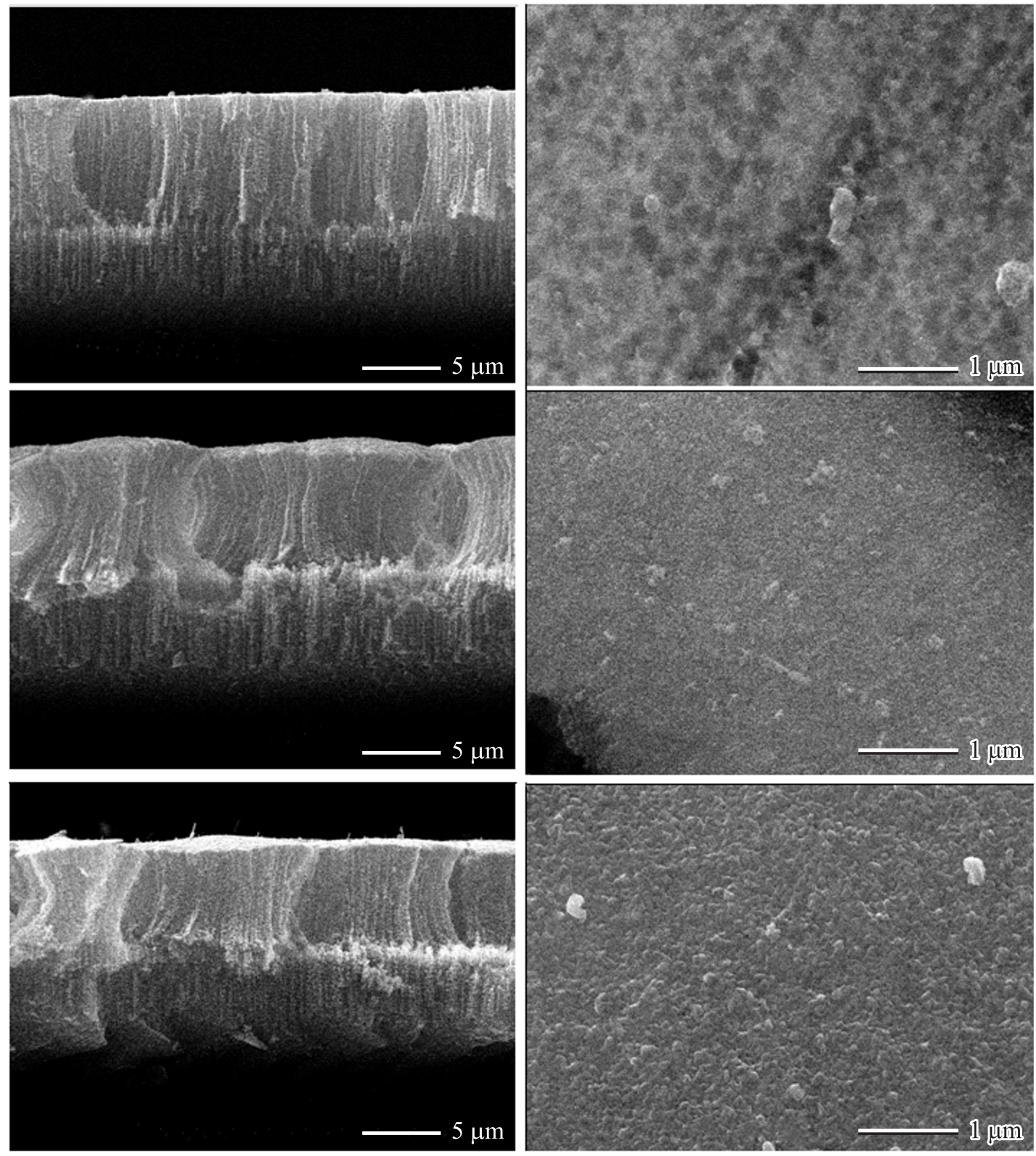

Рис. 1. РЭМ-изображения сколов (слева) и поверхности образцов (справа) исходного пористого кремния (верхний ряд) и нанокомпозитов $\mathrm{Sn} /$ por-Si с тонким слоем олова (средний ряд) и более толстым слоем олова (нижний ряд).

на основе плавиковой кислоты, изопропилового спирта и перекиси водорода [13]. Анодное травление пластин проводилось в течение $10 \mathrm{~min}$ при плотности тока $15 \mathrm{~mA} / \mathrm{cm}^{2}$ с последующей промывкой в воде и изопропаноле. Пористый слой формировался одновременно с двух сторон пластины, на одну из которых впоследствии наносилось олово для получения нанокомпозита $\mathrm{Sn} /$ por-Si.

Осаждение пленок олова проводилось методом магнетронного распыления в плазмообразующей среде аргона. Остаточное давление в камере магнетрона составляло $5 \cdot 10^{6}$ Torr, давление аргона $10^{-3}$ Torr, разрядный ток $60 \mathrm{~mA}$, напряжение $380 \mathrm{~V}$. Осаждение проходило при комнатной температуре, мишенью служило металличе- ское олово марки осч. Согласно калибровочным экспериментам, скорость осаждения металлической пленки в указанном режиме составляет $\sim 1 \mathrm{~nm} / \mathrm{s}$. Время осаждения пленок олова на пористый кремний для исследуемых образцов $t=20$ и $50 \mathrm{~s}$.

Растровые изображения поверхности образцов были получены на электронном микроскопе JEOL-JSM 6380LV. Исследования состава поверхности образцов исходного por-Si и нанокомпозитов (HK) Sn/por-Si различной толщины проводились с использованием методов рентгеновской фотоэлектронной, спектроскопии XPS ( $X$-ray photoelectron spectroscopy). Исследования образцов методом XPS были выполнены на лабораторном спектрометре фирмы SPECS, возбуждение $\operatorname{Mg} K_{\alpha}$. Ана- 


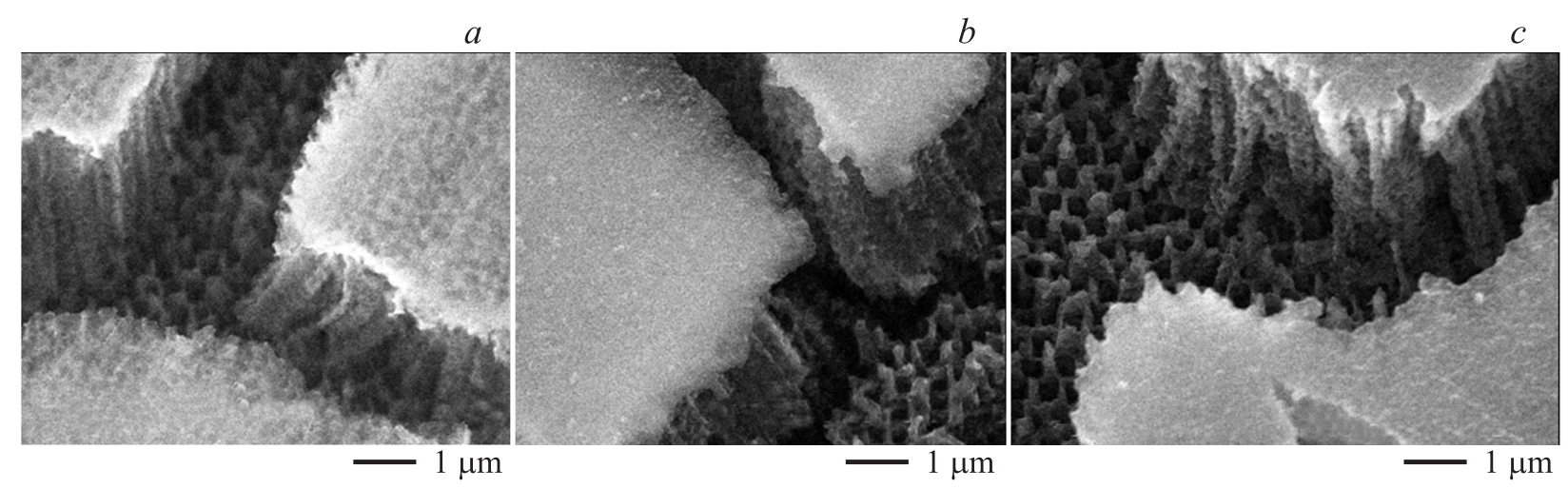

Рис. 2. РЭМ-изображения поверхности исходного пористого кремния $(a)$, тонкого $(b)$ и толстого $(c)$ композитов.

лиз состава образцов композитов указанным методом проводился как в поверхностных слоях $\sim 1 \mathrm{~nm}$, так и на различной глубине, задаваемой временем травления образца. Травление поверхности в течение 1 и $3 \mathrm{~min}$ осуществлялось ионами аргона с энергией $4 \mathrm{keV}$, плотность ионного тока составляла $30 \mu \mathrm{A} / \mathrm{cm}^{2}$, скорость травления образцов $2-2.5 \mathrm{~nm} / \mathrm{min}$. Таким образом, глубина анализа образцов при применении данной методики составляла от $\sim 1-2$ до $7 \mathrm{~nm}$.

Обработка экспериментальных данных осуществлялась при помощи программного пакета Origin 9.0. Методика определения линии фона и его вычитание согласно алгоритмам, предложенным Ширли [14], также были реализованы с помощью данной программы. При определении энергий связи остовных уровней элементов нанокомпозита в качестве реперной была использована энергия линии $\mathrm{C} 1 s$ естественных углеводородных загрязнений поверхности любого образца, не подвергнутого специальной очистке, приведенная к энергии $E_{b}[\mathrm{C} 1 s]=285 \mathrm{eV}$. Идентификация XPS остовных уровней элементов и их химического состояния проводилась с использованием базы данных рентгеновских фотоэлектронных спектров Национального института стандартов США [15].

\section{3. Результаты и обсуждение}

3.1. Особенности морфологии нанокомпозитов $\mathrm{Sn} /$ por-Si co слоями олова различной толщины. На рис. 1 представлены РЭМ-изображения скола и поверхности исходного por-Si и пористого кремния с осажденным оловом $\mathrm{Sn} /$ por-Si.

Образцы исходного por-Si имеют морфологию, характерную для образцов пористого кремния [6,13], полученных по описанной в данной работе методике. На поверхности и сколе образцов наблюдаются вертикально ориентированные поры диаметром 50-150 nm. Толщина пористого слоя образцов составила $\sim 10-12 \mu \mathrm{m}$.

Осаждение олова магнетронным методом в течение 20 и $50 \mathrm{~s}$ привело к формированию тонких полупрозрачных пленок на поверхности пористого кремния. Результаты РЭМ (рис. 1) показывают, что поверхность образцов $\mathrm{Sn} /$ por-Si становится более гладкой, чем в случае исходного пористого слоя. На РЭМ-изображении поверхности более тонкой пленки просматривается морфология скрытого под ней пористого слоя, которая у более толстой пленки не наблюдается.

Кроме того, на поверхности por-Si и образцов $\mathrm{Sn} /$ por-Si наблюдаются макротрещины (рис. 2), возникающие, по-видимому, вследствие механических напряжений в процессе естественного окисления и манипулирования с образцами. При этом осаждение олова по данным РЭМ приводит к дополнительной деформации пористого слоя. Бо́льшая глубина резкости на РЭМ-изображениях образцов $\mathrm{Sn} /$ por-Si, чем для por-Si (рис. 2), может объясняться декорирующим действием олова, которое при осаждении проникает в глубь пор и осаждается на боковых поверхностях кремниевых наностолбов.

3.2. Состав нанокомпозитов Sn/por-Si paзличной толщины по данным XPS.

3.2.1. Обзорные спектры XPS. Обзорные XPS-спектры и спектры остовных уровней образцов исходного por-Si и HK $\mathrm{Sn} /$ por-Si были измерены на лабораторном спектрометре фирмы SPECS ФТИ УрО РАН по методике, описанной выше и аналогичной использованной в работе [16]. Съемка образцов проводилась без травления и с травлением аргонной пушкой в течение 1 и $3 \mathrm{~min}$. На рис. 3 представлены обзорные XPS-спектры por-Si и НК $\mathrm{Sn} /$ por-Si с осажденной в течение $20 \mathrm{~s}$ пленкой олова, измеренные после $3 \mathrm{~min}$ травления ионной пушкой. Обзорные спектры НК с более толстым слоем олова идентичны обзорным спектрам НК с тонким слоем Sn.

Анализ обзорных XPS-спектров показывает, что на всех исследованных нами образцах присутствует некоторое количество естественных углеводородных загрязнений, уменьшающееся в результате травления поверхности ионами аргона. На обзорных XPS-спектрах образца исходного por-Si присутствуют линии, соответствующие остовным уровням $\mathrm{Si} 2 p\left(E_{b}=99-104 \mathrm{eV}\right)$, 

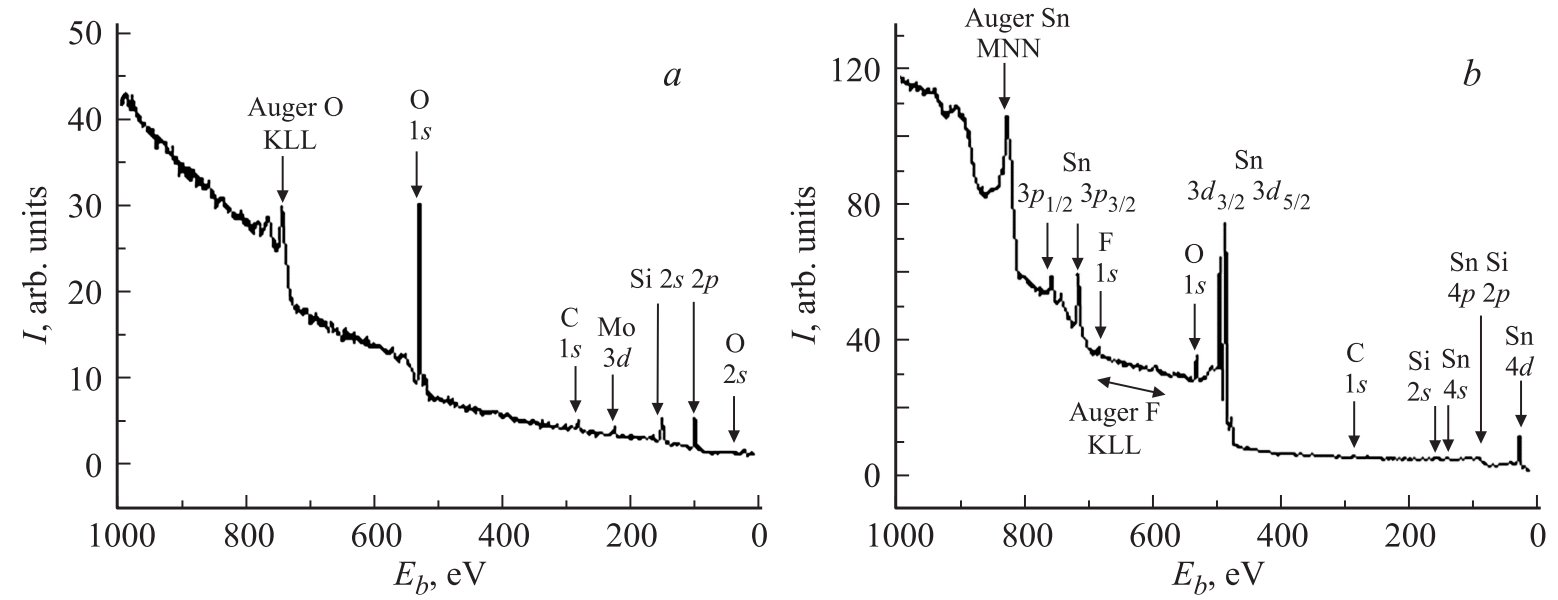

Рис. 3. Обзорные XPS-спектры пористого кремния $(a)$ и тонкого композита $(b)$.
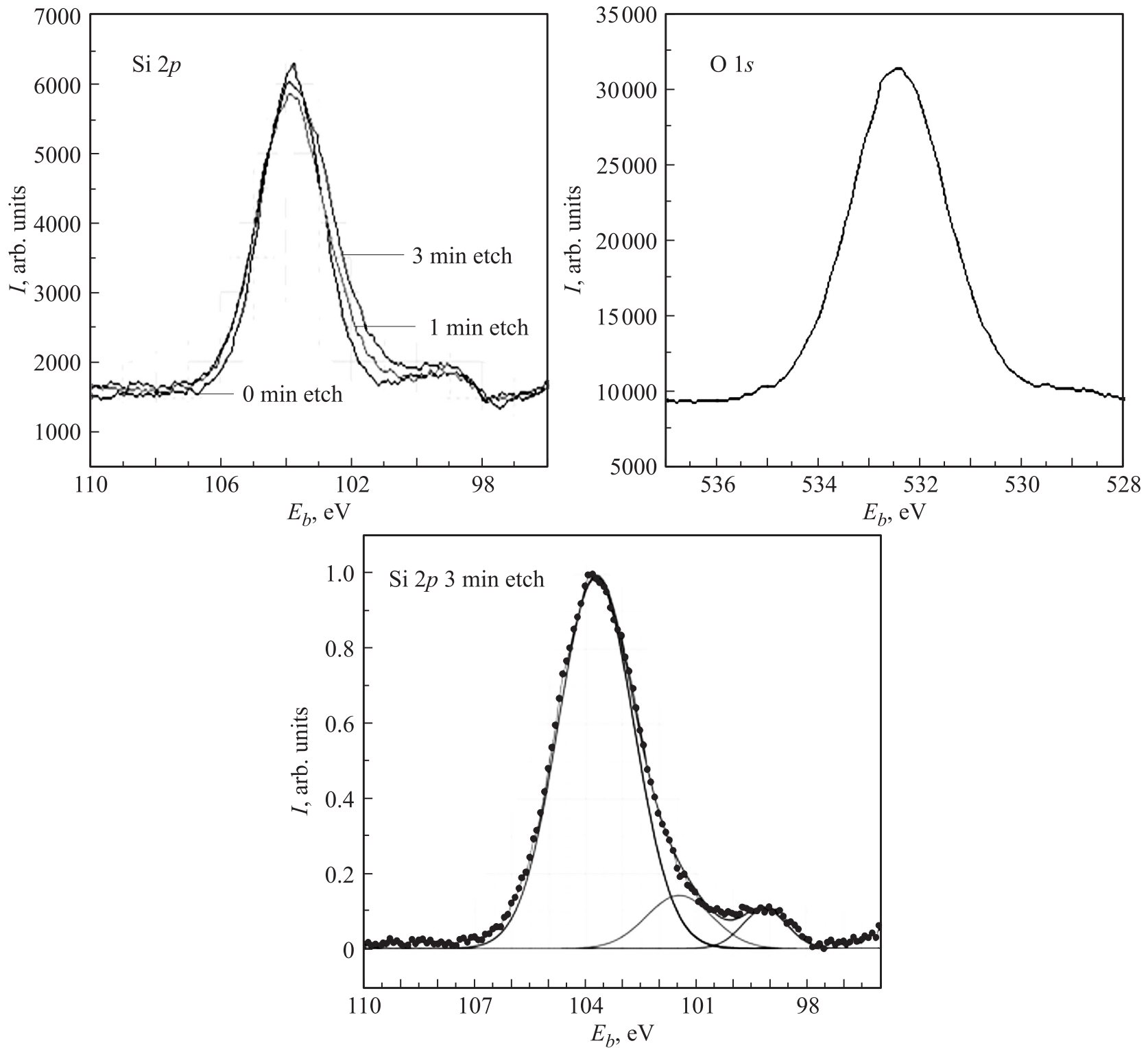

Рис. 4. XPS Si $2 p$-спектры исходного пористого кремния для разной глубины анализа, O $1 s$-спектр por-Si после 3 min травления, $\mathrm{Si} 2 p$-спектр por-Si после 3 min травления с разложением на компоненты. 

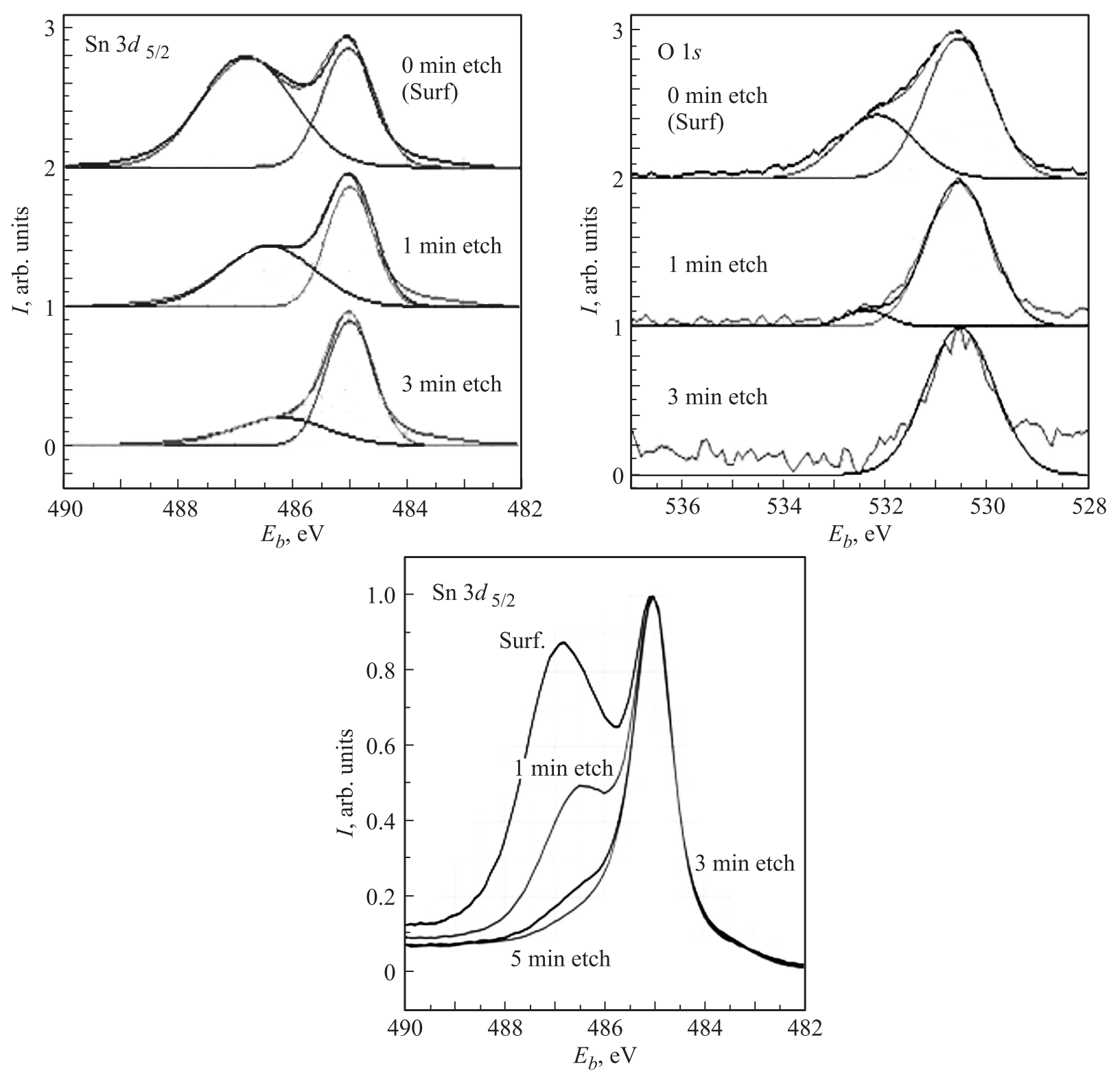

Рис. 5. Эталонные спектры XPS Sn $3 d_{5 / 2}$ и O $1 s$ фольги олова с разложением на компоненты для разной глубины анализа $(\sim 1,3,7 \mathrm{~nm})$.

Si $2 s(150-155 \mathrm{eV})$, O $1 s(530-533 \mathrm{eV})$, C $1 s(285 \mathrm{eV})$, также в спектрах наблюдается линия, соответствующая остовному уровню молибдена Мо $3 d(229-231 \mathrm{eV})$, из которого в спектрометре сделан держатель образцов. На обзорном спектре образцов HK Sn/por-Si наряду с этими уровнями наиболее интенсивными являются остовные уровни олова Sn $4 d(24-27 \mathrm{eV}), \mathrm{Sn} 4 p(85-86 \mathrm{eV}), \mathrm{Sn} 3 d$ $(482-492 \mathrm{eV})$ и $\mathrm{Sn} 3 p(714-717 \mathrm{eV})$.

Для более точного определения энергетического положения остовных уровней и последующего анализа фазового состава нанокомпозитов были получены спектры XPS остовных уровней элементов, входящих в состав образцов.

3.2.2. Спектры XPS исходного пористого кремния. На рис. 4 представлены XPS Si $2 p$-спектры исходного пористого кремния, О $1 s$-спектр и разло- женный на компоненты $\mathrm{Si} 2 p$-спектр этого же образца после травления ионной пушкой в течение $3 \mathrm{~min}$. Анализ $\mathrm{Si} 2 p$-спектров показывает, что полученные данные по составу „мезопористого“ кремния хорошо согласуются с известными литературными данными. Ранее нами было установлено $[16,17]$, что поверхностные слои пористого кремния состоят из диоксида кремния ( $\left.\mathrm{Si} 2 p, E_{b}=103.5 \mathrm{eV}\right)$, субоксидов кремния $\left(\mathrm{Si} 2 p, E_{b}=100.5-103 \mathrm{eV}\right)$ и неокисленного кремния в кристаллическом или аморфном состоянии ( $\mathrm{Si} 2 p$, $\left.E_{b}=99.5 \mathrm{eV}\right)$. При этом известно и многократно подтверждено, что со временем хранения доля оксидных фаз в пористом слое растет, особенно в поверхностных слоях.

Из XPS Si $2 p$-спектров por-Si (pис. 4) следует, что как в исходном образце, так и в образце после его 

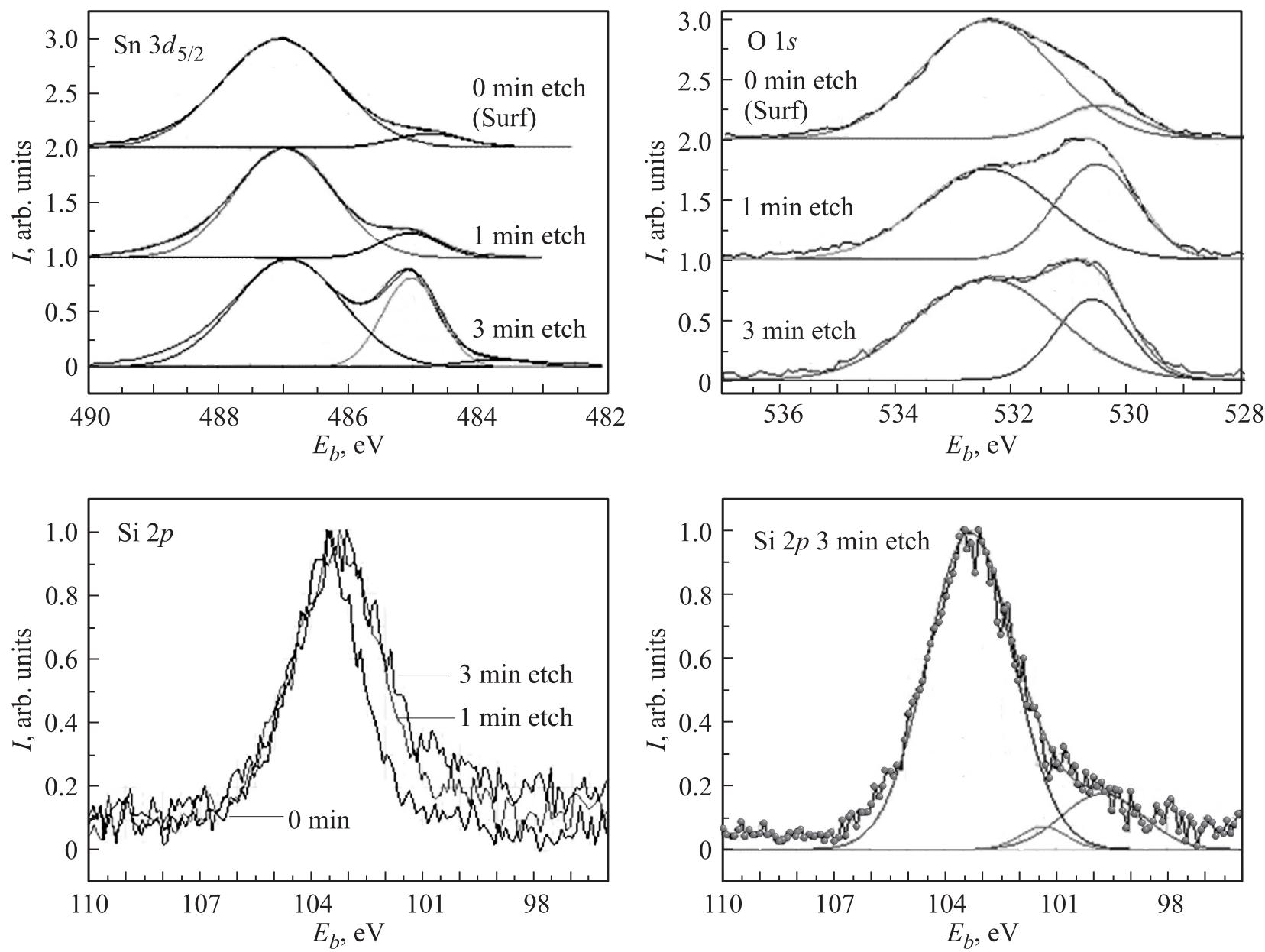

Pис. 6. XPS Sn $3 d_{5 / 2^{-}}$и O $1 s$-спектры толстого композита $\mathrm{Sn} /$ por-Si с разложением на компоненты для разной глубины анализа $(\sim 1,3,7 \mathrm{~nm})$, а также его Si $2 p$-спектры.

трехминутного травления в поверхностных слоях пористого слоя преобладает диоксид кремния $(\mathrm{Si} 2 p$, $\left.E_{b}=103.5 \mathrm{eV}\right)$. Вместе с тем после удаления поверхностного слоя в течение $3 \mathrm{~min}$ минут более отчетливо проявляются слабые компоненты в области энергий связи 99-103 eV, соответствующие элементарному кремнию $(\sim 99.5 \mathrm{eV})$ и его субоксидам.

XPS O $1 s$-спектр пористого кремния с максимумом при $532.5 \mathrm{eV}$ соответствует линии связанного кислорода в диоксиде кремния и совпадает со спектром адсорбированного на поверхности образца кислорода, имеющего энергию связи в области 530-534 eV.

3.2.3. Эталонные XPS-спектры фольги металлического олова. На рис. 5 представлены XPS-спектры остовных уровней $\mathrm{Sn} 3 d_{5 / 2}$ и О $1 s$ фольги металлического олова, использовавшиеся в качестве эталонных, полученные как без травления образцов, так и с травлением ионами аргона в течение 1-5 min. Анализ формы и положения XPS Sn $3 d_{5 / 2}$-спектра и их математическое моделирование показывают, что олово в поверхностном слое фольги находится в виде металлического $\mathrm{Sn}$ (компонента спектра с $E_{b}=485 \mathrm{eV}$ ) и естественного оксида $\mathrm{SnO}_{x}$, где $x \approx 2\left(E_{b}=486.5-487 \mathrm{eV}\right)$.
При этом с увеличением глубины анализа общее содержание оксида в объеме анализируемого слоя значительно уменьшается с одновременным уменьшением степени окисления от поверхности к объему образца, что проявляется в сдвиге максимума субоксидной компоненты в сторону меньших энергий связи по сравнению c $\mathrm{SnO}_{2}$.

Анализ О $1 s$-спектров фольги олова подтверждает наличие естественного оксида олова в поверхностном слое фольги (компонента с $E_{b}=530.5 \mathrm{eV}$ ) и указывает на уменьшение содержания адсорбированного кислорода с увеличением глубины анализа при стравливании поверхностных слоев фольги. При времени травления 3 min компонента спектра адсорбированного кислорода с $E_{b}=532.5 \mathrm{eV}$ исчезает и остается лишь компонента связанного кислорода субоксида олова.

3.2.4. Композит $\mathrm{Sn} /$ por-Si с толстым $(\sim 50 \mathrm{~nm})$ слоем нанесенного олова. На рис. 6 представлены спектры XPS остовных уровней $\mathrm{Sn} 3 d_{5 / 2}$, $\mathrm{O} 1 s$ и $\mathrm{Si} 2 p$, полученные до и после трехминутного ионного травления образца $\mathrm{Sn} /$ por-Si с пленкой олова, напыляемой в магнетроне в течение $50 \mathrm{~s}$, который будем называть „толстым“. 

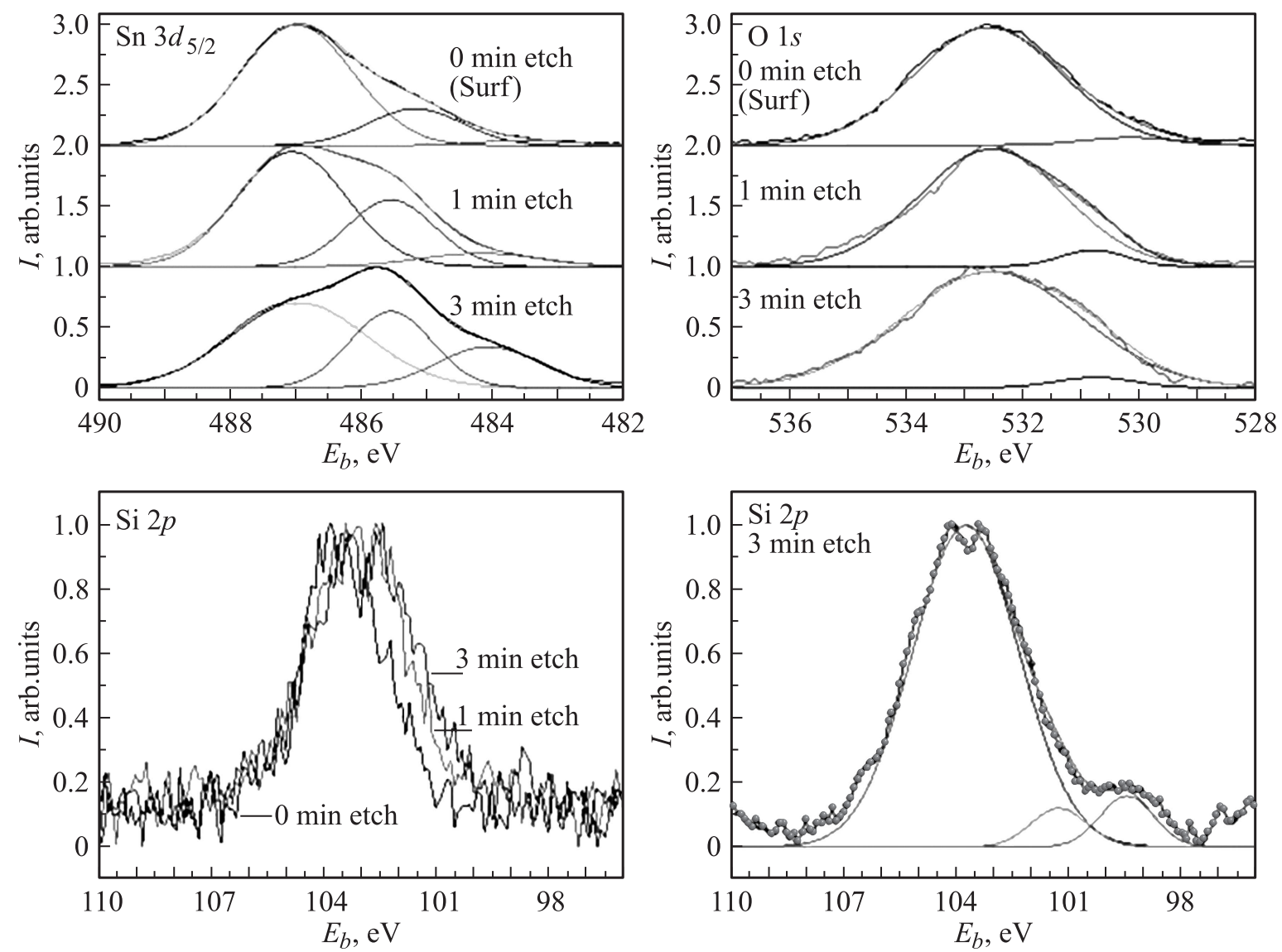

Рис. 7. XPS Sn $3 d_{5 / 2}$ и O $1 s$-спектры тонкого композита $\mathrm{Sn} /$ por-Si с разложением на компоненты для разной глубины анализа $(\sim 1,3,7 \mathrm{~nm})$, а также его Si $2 p$-спектры.

Анализ и разложение на компоненты XPS Sn $3 d_{5 / 2^{-}}$ спектра образца с толстой пленкой олова показывают, что олово на поверхности композита состоит преимущественно из диоксида олова $\left(E_{b}=487 \mathrm{eV}\right)$ с небольшой долей неокисленного олова $\left(E_{b}=485 \mathrm{eV}\right)$.

С увеличением глубины анализа вклад компоненты от металлического олова в спектр заметно возрастает. Следует сразу отметить существенное отличие фазового состава олова во всех исследованных слоях нанокомпозитного образца $\mathrm{Sn} /$ por-Si от характерного для металлической фольги, покрытой естественным оксидным слоем. Если в поверхностном слое фольги до травления в спектре XPS Sn $3 d_{5 / 2}$ преобладает компонента металла $\left(E_{b}=485.0 \mathrm{eV}\right)$, то в спектре нанокомпозита эта металлическая компонента лишь намечается в виде низкоэнергетического хвоста $\mathrm{Sn} 3 d_{5 / 2}$ спектра. Соответствующим образом ведет себя и XPS О $1 s$-спектр, который в нанокомпозите также содержит две компоненты, одна из которых соответствует кислороду оксида кремния $\mathrm{SiO}_{x}$ и адсорбированному на поверхности кислороду с $E_{b}=532.5 \mathrm{eV}$, а вторая - кислороду оксида олова $\mathrm{SnO}_{2}$ с $E_{b}=530.5 \mathrm{eV}$. $\mathrm{C}$ увеличением глубины анализа вклад в спектр компоненты оксида олова увеличивается, как и объемном эталоне. Однако вклад компоненты адсорбированного кислорода и совпадающей с ней компоненты от оксида кремния остается преобладающим и при ионном травлении образца.

XPS Si $2 p$-спектры толстого нанокомпозита $\mathrm{Sn} /$ por-Si при низкой интенсивности на фоне шумов показывают наличие в композитном слое связей, характерных для окисленного кремния (область спектра с $\left.E_{b}\left(\mathrm{SiO}_{x}\right)=100.5-103.5 \mathrm{eV}\right)$ со следами элементарного кремния $E_{b}(\mathrm{Si})=99.5 \mathrm{eV}$.

C учетом низкой интенсивности спектра соотношение этих связей и их изменение от поверхности к объему приблизительно соответствуют составу исходной подложки por-Si. Исследование обратной стороны образцов с аналогичным пористым слоем без пленки также показало отсутствие влияния параметров осаждения (температуры, давления, паров аргона) на поверхность пористого кремния.

3.2.5. Композит $\mathrm{Sn} /$ por-Si c тонким слоем $(\sim 20 \mathrm{~nm})$ нанесенного олова. На рис. 7 представлены XPS-спектры остовных уровней Sn $3 d_{5 / 2}$, O $1 s$ и $\mathrm{Si} 2 p$ образца $\mathrm{Sn} /$ por-Si с нанесенной в течение $20 \mathrm{~s}$ пленкой олова, называемого нами „тонким“, до и после ионного травления, а также разложенный на компоненты Si $2 p$-спектр этого же образца после 3 min травления ионной пушкой. 

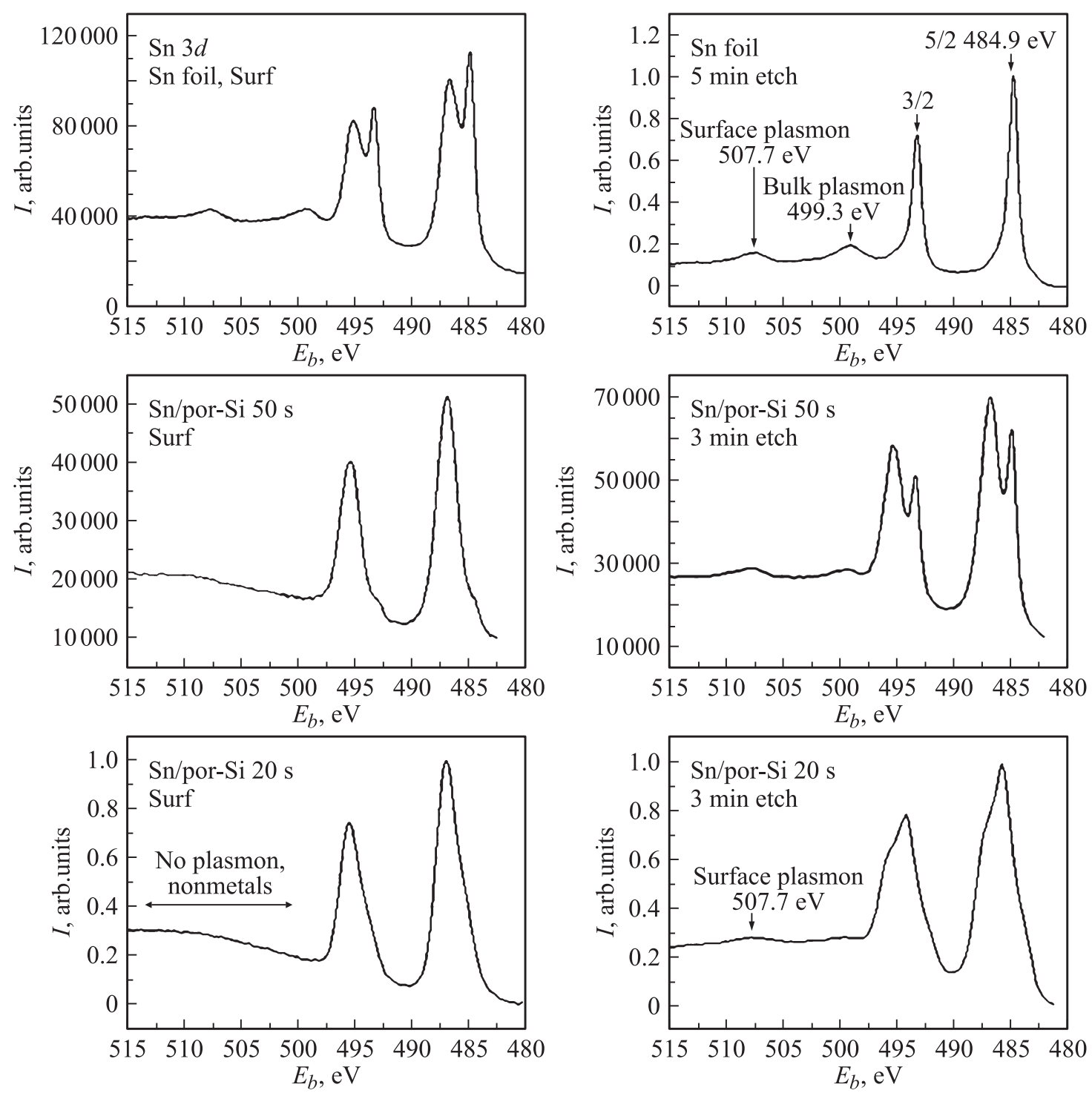

Рис. 8. XPS Sn $3 d$-спектры эталонной фольги (в широком диапазоне), толстого и тонкого композита $\mathrm{Sn} / \mathrm{por}-\mathrm{Si}$ без травления и после травления в течение $3 \mathrm{~min}$.

Анализ формы и положения XPS Sn $3 d_{5 / 2}$-спектра образца и их математическое моделирование показывают, что олово в поверхностных слоях образца присутствует в основном в виде диоксида $\mathrm{SnO}_{2}(487.0 \mathrm{eV})$ и субоксида олова $\mathrm{SnO}_{x}$, где $x \approx 1(485.3-485.6 \mathrm{eV})$. И только с увеличением глубины анализа после травления ионным пучком в композитном слое появляется металлическое олово, проявляющееся в спектре в виде особенности с пиком $484.2 \mathrm{eV}$ и общего уширения XPS Sn $3 d_{5 / 2}$-полосы спектра.

В результате после травления спектр XPS Sn $3 d_{5 / 2}$ образца $\mathrm{Sn} /$ por-Si становится трехкомпонентным; его компоненты принадлежат диоксиду олова $\mathrm{SnO}_{2}(487.0 \mathrm{eV})$, субоксиду олова, близкому к монооксиду $\mathrm{SnO}$, и нанокристаллическому металлическому олову с энергией связи $E_{b}(\mathrm{Sn})=484.2 \mathrm{eV}$. При этом в отличие от металлической фольги ни у толстого, ни у тонкого нанокомпозита с увеличением глубины анализа при общем снижении вклада окисленного олова в фазовый состав не наблюдается вариации состава естественного оксида, потому что компоненты диоксида и субоксида не изменяют своего энергетического положения (см. таблицу). Это указывает на то, что в композитах $\mathrm{Sn} /$ por-Si отсутствует залегающий на определенной глубине металлический интерфейс, в области которого происходит снижение степени окисления $\mathrm{SnO}_{2}$.

XPS O $1 s$-спектр в тонком нанокомпозите содержит по существу одну компоненту, принадлежащую кислороду оксида кремния $\mathrm{SiO}_{x}$ и адсорбированному на поверхности кислороду с $E_{b}=532.5 \mathrm{eV}$. Вторая компонента кислорода, принадлежащая оксиду олова $\mathrm{SnO}_{2}$ с $E_{b}=530.5 \mathrm{eV}$, остается малоинтенсивной ввиду очень малой толщины оловосодержащего композитного слоя.

Анализ XPS Si $2 p$-спектров пористого кремния в композитном слое образца $\mathrm{Sn} /$ por-Si с нанесенной тонкой пленкой при низкой интенсивности на фоне шумов 
Значения энергий связи $E_{b}($ в $\mathrm{eV})$ остовных уровней в исследуемых образцах

\begin{tabular}{|c|c|c|c|c|c|c|c|c|c|c|c|c|c|}
\hline \multirow{3}{*}{$\begin{array}{l}\text { Полоса } \\
\text { спектра }\end{array}$} & \multirow{2}{*}{\multicolumn{3}{|c|}{ por-Si }} & \multicolumn{6}{|c|}{$\mathrm{Sn} /$ por-Si } & \multirow{2}{*}{\multicolumn{3}{|c|}{ Sn-фольга (эталон) }} & \multirow{3}{*}{ Компонент } \\
\hline & & & & \multicolumn{3}{|c|}{ Тонкий слой Sn } & \multicolumn{3}{|c|}{ Толстый слой Sn } & & & & \\
\hline & 0 & $1 \mathrm{~min}$ & $3 \mathrm{~min}$ & 0 & $1 \mathrm{~min}$ & $3 \mathrm{~min}$ & 0 & $1 \mathrm{~min}$ & $3 \mathrm{~min}$ & 0 & $1 \mathrm{~min}$ & $3 \mathrm{~min}$ & \\
\hline \multirow[t]{3}{*}{ Sn $3 d_{5 / 2}$} & - & - & - & 487.0 & 487.0 & 487.0 & 487.0 & 487.0 & 487.0 & 486.9 & 486.5 & 486.4 & $\mathrm{SnO}_{2}$ \\
\hline & - & - & - & 485.3 & 485.5 & 485.5 & - & - & - & - & - & - & $\mathrm{SnO}_{x}$ \\
\hline & - & - & - & - & 484.2 & 484.2 & 485.0 & 485.0 & 485.0 & 485.0 & 485.0 & 485.0 & Sn \\
\hline \multirow[t]{2}{*}{$\mathrm{O} 1 s$} & 532.5 & 532.5 & 532.5 & 532.5 & 532.5 & 532.5 & 532.5 & 532.5 & 532.5 & 532.4 & 532.5 & - & $\mathrm{SiO}_{2}+$ адсорбированный $\mathrm{O}$ \\
\hline & - & - & - & $-/ 530.5^{*}$ & 530.5 & 530.5 & 530.5 & 530.5 & 530.5 & 530.5 & 530.5 & 530.5 & $\mathrm{SnO}_{2}$ \\
\hline \multirow[t]{3}{*}{ Si $2 p$} & 103.5 & 103.5 & 103.5 & 103.5 & 103.5 & 103.5 & 103.5 & 103.5 & 103.5 & - & - & - & $\mathrm{SiO}_{2}$ \\
\hline & 101.5 & 101.5 & 101.5 & 101.5 & 101.5 & 101.5 & 101.5 & 101.5 & 101.5 & - & - & - & $\mathrm{SiO}_{x}$ \\
\hline & 99.5 & 99.5 & 99.5 & 99.5 & 99.5 & 99.5 & 99.5 & 99.5 & 99.5 & - & - & - & $\mathrm{Si}$ \\
\hline
\end{tabular}

* На уровне следов.

показывает примерно такой же компонентный состав, как и в случае исходной положки и композита с толстой пленкой, в котором преобладает диоксид кремния с небольшой добавкой субоксида и элементарного кремния, т.е. по результатам исследования методом XPS нанесение описанным в работе магнетронным методом тонких слоев олова практически не оказывает влияния на фазовый состав подложки пористого кремния.

Чтобы убедиться в существовании нанокристаллов металлического олова в образце $\mathrm{Sn} /$ por-Si c тонкой пленкой олова после трехминутного ионного травления, мы измерили спектры XPS Sn $3 d$ этого образца в сравнении со спектром эталонной фольги и более толстого образца (до и после травления ионной пушкой) в более широком диапазоне энергий для регистрации спектров плазмонов. На рис. 8 представлены XPS Sn $3 d$-спектры этих образцов, на которых в металлической фольге после пятиминутного ионного травления зарегистрированы спектры объемных плазмонов (более интенсивный пик при $499.3 \mathrm{eV}$ ) и поверхностных плазмонов при $507.7 \mathrm{eV}$. В более толстом нанокомпозите после травления пик поверхностного плазмона становится более выразительным по сравнению с объемным. В тонком образце последний практически полностью исчезает, т.е. для металлических нанокристаллов олова тонкого нанокомпозитного образца $\mathrm{Sn} /$ por-Si проявляются преимущественно поверхностные плазмоны, как и следовало ожидать для малых частиц металла.

\section{4. Заключение}

Исследование образцов пористого кремния с осажденными магнетронным распылением тонкими слоями олова разной (различающейся более чем в 2 раза) толщины методами растровой электронной микроскопии и рентгеновской фотоэлектронной спектроскопии показало, что сформированные в поверхностных слоях образцов нанокомпозиты различаются между собой соотношением основных фаз: диоксида олова, субоксида/монооксида олова и металлического олова, и соотношение этих фаз существенно отличается от наблюдаемого в поверхностных слоях металлической фольги олова (до $\sim 7 \mathrm{~nm}$ ) с ионным травлением в сторону преобладания оксидных и субоксидных фаз олова в нанокомпозитах.

Данные микроскопии образцов с нанесенными пленками $\mathrm{Sn} /$ por-Si указывают на образование покрывающего слоя как на поверхности por-Si, так и в более глубоких слоях. Поэтому, когда толщина покрывающего слоя тонкой пленки олова сопоставима с глубиной анализа используемой методики, в XPS Sn $3 d$-спектрах проявляется наряду с диоксид/субоксидным слоем нанокристаллическое металлическое олово с минимальной энергией связи остовного уровня $\mathrm{Sn} 3 d_{5 / 2}$. Наличие нанокристаллов олова в более тонком композите подтверждено наблюдением уровня поверхностных плазмонов при $507.7 \mathrm{eV}$

Следует особо подчеркнуть, что осаждение нанослоев олова не приводит к значительному изменению фазового состава подложки пористого кремния por-Si, состоящего по данным XPS преимущественно из диоксида кремния с небольшой добавкой элементарного кремния и промежуточного субоксида кремния.

\section{Список литературы}

[1] Ю.А. Жарова, Г.В. Федулова, Е.В. Астрова, А.В. Балдычева, В.А. Толмачев, Т.С. Перова. ФТП 45, 8, 1136 (2011).

[2] L.Yu. Kupriyanov. Semiconductor sensors in physicochemical studies. Elsevier, Amsterdam (1996). 400 p.

[3] A.S. Lenshin, V.M. Kashkarov, Yu.M. Spivak, V.A. Moshnikov. Mater. Chem. Phys. 135, 2-3, 293 (2012).

[4] V.A. Moshnikov, I. Gracheva, A.S. Lenshin, Y.M. Spivak, M.G. Anchkov, V.V. Kuznetsov, J.M. Olchowik. J. Non-Cryst. Solids 358, 3, 590 (2012).

[5] А.В. Шапошник, А.А. Звягин, С.Н. Корчагина, С.В. Рябцев, Д.А. Шапошник. Сорбционные и хроматографические процессы 12, 2, 261 (2012).

[6] А.С. Леньшин, П.В. Середин, Д.А. Минаков, В.М. Кашкаров, Б.Л. Агапов, Э.П. Домашевская, И.Е. Кононова, В.А. Мошников, Н.С. Теребова, И.Н. Шабанова. ФТП 48, 4, 570 (2014). 
[7] Ю.А. Вашпанов, В.А. Смынтына. Адсорбционная чувствительность полупроводников. Астропринт, Одесса (2005). $216 \mathrm{c}$.

[8] Y.-J. Hsu, S.-Y. Lu. J. Phys. Chem. B 109, 4398 (2005).

[9] N.-S. Choi, Y. Yao, Y. Cui, J. Cho. J. Mater. Chem. 21, 9825 (2011).

[10] И.А. Аверин, С.Е. Игошина, В.А. Мошников, А.А. Карманов, И.А. Пронин, И.Е. Теруков. ЖТФ 85, 6, 143 (2015).

[11] Ю.А. Юраков, С.В. Рябцев, О.А. Чувенкова, Э.П. Домашевская, А.С. Никитенко, С.В. Канныкин, С.Б. Кущев. Кристаллография 54, 1, 116 (2009).

[12] С.В. Рябцев, О.А. Чувенкова, А.Е. Попов, Ф.М. Чернышов, Н.С. Рябцева, Э.П. Домашевская. Конденсированные среды и межфазные границы 14, 3, 328 (2012).

[13] A.S. Lenshin, P.V. Seredin, B.L. Agapov, D.A. Minakov, V.M. Kashkarov. Mater. Sci. Semicond. Proc. 30, 25 (2015).

[14] D.A. Shirley. Phys. Rev. B 5, 4709 (1972).

[15] NIST $X$-ray photoelectron spectroscopy database; $\mathrm{http}: / /$ srdata.nist.gov/xps.

[16] A.S. Lenshin, V.M. Kashkarov, E.P. Domashevskaya, A.N. Bel'tyukov, F.Z. Gil'mutdinov. Appl. Surf. Sci. 359, 550 (2015).

[17] А.С. Леньшин, В.М. Кашкаров, С.Ю. Турищев, М.С. Смирнов, Э.П. Домашевская. ЖТФ 82, 2, 150 (2012). 